\title{
LA EQUIDAD: UNA JUSTICIA MÁS JUSTA
}

\author{
Isabel RUIZ-GALLARDÓN \\ Departamento de Ciencias \\ de la Comunicación y Sociología \\ Universidad Rey Juan Carlos \\ isabel.ruizgallardon@urjc.es
}

\begin{abstract}
RESUMEN
El concepto de epiqueya fue introducido por Aristóteles en la Ética a Nicómaco $(V, 4)$ para corregir la aplicación de una ley general y abstracta a un caso en que, sin hacer ningún tipo de distinción, resultaría contrario a la justicia. Esta idea ha pervivido, sobre todo en la contraposición entre un ius strictum, necesitado de una adecuación, y un ius aequum. Hoy la equidad se entiende como el criterio de justicia que toma en consideración no sólo el sistema jurídico, sino también las particularidades del caso, y que trata de darle una solución con un sentido moral y bumano más que estrictamente legal. Similar a ésta es la consideración de la equidad como una separación de la letra de la ley para centrarse en su espíritu. Todo esto sin olvidar que en la raíz de la palabra latina aequitas se encuentra el elemento de la igualdad, de especial importancia en los casos en que la justicia que se pone en juego tiene un carácter distributivo, y sin olvidar que la importancia de la equidad es tal en los sistemas jurídicos angloamericanos que la equity es fuente de Derecho.
\end{abstract}

Palabras clave: equidad, justicia, Derecho, ética, Derecho estricto, Derecho justo.

\section{ABSTRACT}

The term epiqueya was introduced by Aristotle in his book Nichomachean Ethics $(V, 4)$ in order to improve a general or abstract law that applies in a given case where, with no distinction whatsoever, it would end up being contrary to justice. Such idea has gone down in history, particularly when opposing ius strictum, in need of adequacy and ius aequum. Nowadays equity is considered to be the justice criteria which does not only take into account the legal system but also the specifics of the given case and which aims at bringing an answer within a more moral and human sense and not just within a legal one. On the same lines equity tends to be considered a spin off of the wording in order to focus on its essence. And yet we should not forget that on the foundations of the latin word aequitas there is an element of equality, particularly important in cases of justice of distributive justice; let alone the importance of equity in Saxon American Legal systems, where Equity is source of Right.

Keywords: Equity, Justice, Law, Ethics, Pure law, Fair Law.

\section{ZUSSAMENFASSUNG}

Das Konzept der epiqueya wurde von Aristoteles in seiner Nikomachischen Ethik $(V, 4)$ eingefübrt, um die Anwendung eines allgemeinen und abstrakten Gesetz zu 
korrigieren, das im vorgelegten Fall, obne die Anstrengung der Unterscheidung, eine gegenteilige Rechtssprechung zur Folge hätte. Diese Idee hat fortgelebt, vor allem in der Gegenüberstellung zwischen dem ius strictum, welches einer Billigkeit bedarf, und dem ius aequum. Heute versteht sich die "Billigkeit" als juristisches Kriterium, welches nicht nur das Rechtssystem im Auge hat, sondern auch die Besonderbeiten des Falls und dadurch bemübt ist, eine eber moralische und bumane Lösung zu finden, statt einer juristischen im eng ausgelegten Sinne. Ähnlich dazu verbält sich die Auffassung der Billigkeit als einer Anschaunng, die den Wortlaut des Gesetzes vom Geist des Gesetzes trennt. Dies alles jedoch obne zu vergessen, dass sich in der lateinischen Wortwurzel aequitas das Element der Gleichbeit befindet, welches eine besondere Rolle spielt, wenn es bei Gerichtsprozessen um die Verteilung gebt. Ebenso sollte nicht vergessen werden, dass die Bedeutung der Billigkeit und Gleichbeit in den angloamerikanischen Justizsystemen im Rechtsbegriff Equity zur Quelle des Rechts wird.

Schlüsselwörter: Billigkeit, Gleichbeit, Gerechtigkeit, Recht, Ethik, Strenges Recht, Gerechtes Recht.

SUMARIO: I. PRECISIONES LINGÜÍSTICAS EN TORNO AL CONCEPTO DE EQUIDAD.-II. CONFIGURACIÓN HISTÓRICA DE LA EQUIDAD.III. PROPUESTA DE UN CONCEPTO DE EQUIDAD.-IV. LA APLICACIÓN DE LA EQUIDAD EN VIRTUD DE LA ÉTICA MATERIAL QUE DEBEN TENER LAS NORMAS POSITIVAS.

\section{PRECISIONES LINGÜÍSTICAS EN TORNO AL CONCEPTO DE EQUIDAD}

En todas las culturas superiores de Derecho — dice el profesor Wohlhaupter- «se ha sentido como un problema el que el Derecho positivo, por muy perfecto que sea, nunca puede alcanzar toda la riqueza de las manifestaciones de la vida. Siempre se ve que en muchos casos la aplicación de la ley, según la letra, a un hecho jurídico que, conforme al texto legal, cae dentro de la regla, conduciría a graves injusticias, y también se ve siempre que surgen casos para los cuales las leyes no han previsto solución alguna» ${ }^{1}$.

Supone la equidad una forma de superar la impersonalidad de la justicia sin salir del ámbito formal de la misma. Supone también un impacto o reflejo de la amistad en el campo de la justicia, aun prescindiendo de la concreta motivación amistosa $u$ amorosa que en cada caso pueda determinar su uso o ejercicio. La justicia, en sí misma, existe al margen de la amis-

${ }^{1}$ E. Wohlhaupter, «La importancia de la equidad en la historia del Derecho de España», Revista de Investigación y Progreso, año IV, núm. 10 (1930), p. 105. 
tad, aun cuando, como acto humano, el «trato igual» — que es una forma del respeto debido a la persona- sea también un efecto de la amistad abstractamente concebida. Pero la equidad es fruto de una amistad más concreta (por ejemplo, la amistad entre los ciudadanos de un país o de un grupo social, o del amor al prójimo con el que se está en relación). No obstante, la equidad se mantiene dentro de unos límites en virtud de los cuales sigue siendo aún justicia ${ }^{2}$. Es por esto que la equidad consiste en tomar en cuenta no sólo la justicia estricta en la determinación del Derecho, sino también otras virtudes ${ }^{3}$.

Las aportaciones diversas con que se ha formulado el concepto de equidad explican la variedad de aspectos y significados que tiene dicha palabra tanto en el lenguaje científico como en el vulgar. Todos los aspectos de la equidad corresponden a las múltiples funciones y aplicaciones prácticas de que es susceptible. Así, la llamada equidad natural parece corresponder a la función supletoria respecto al Derecho estatuido, mientras que la equidad civil aparece ligada a su función moderadora o correctiva. Pero no debe resultarnos extraño que existan muchas incertidumbres e imprecisiones en torno a un concepto tan sutil como el de equidad, muy difícil de deslindar de otros conceptos como Derecho y justicia.

Etimológicamente, equidad, como aequitas, entraña la idea romana y clásica de que el fin del Derecho estriba en otorgar igual protección a intereses iguales o semejantes que la merezcan, así como la de que el Derecho debe ser el mismo para todos los miembros de la sociedad ${ }^{4}$. Esta significación de la equidad ha sobrevivido en muchas definiciones doctrinales y en la máxima inglesa «igualdad es equidad» (Equality is Equity).

La palabra equidad también se ha relacionado etimológicamente con la epiqueya aristotélica. En este sentido, la equidad, como igualdad, puede también armonizarse con su sentido de justicia del caso concreto. De este modo, el concepto de la equidad integraría dos elementos: igualdad de trato e individualización de trato; por ello, la equidad es a la vez justicia igualitaria y justicia individualizadora. La equidad, pues, puede imponer tanto la igualdad como la desigualdad. Obliga a tratar igual a los casos iguales y desigual a los desiguales.

${ }^{2}$ L. Legaz y Lacambra, Amor, amistad y justicia, discurso de recepción como académico de número (contestación de Alfonso García Valdecasas), Madrid, Real Academia de Jurisprudencia y Legislación, 1969.

${ }^{3}$ J. HeRvadA, Introducción crítica al Derecho natural, Pamplona, EUNSA, 1987, pp. 60 y ss., e íD., Lecciones de filosofía del Derecho, Pamplona, EUNSA, 1992, pp. 159 y ss.

${ }^{4}$ U. Álunarez, Curso elemental de Derecho romano, vol. 1, Madrid, Estades, 1948, p. 64. 
En términos generales, no cabe duda de que hay una relación, ideológica e histórica, entre la epiqueya de Aristóteles y la aequitas romana. El concepto moderno de la equidad es el resultante de la agrupación de esas dos nociones, en el fondo de las cuales hay una visible coincidencia sustancial. La epiqueya significa, fundamentalmente, una cosa que conviene y que se adapta a otra, una norma que se acomoda a una relación por responder a la íntima naturaleza de ésta; la misma idea de ajuste, adaptación, armonía y unidad la encontramos en la equidad.

Las demás significaciones de la equidad también están entrelazadas. La idea de flexibilidad y de individualización está muy unida a la de benignidad y también a la de equidad como criterio subjetivo o sentimental.

La investigación etimológica nos proporciona, al ponernos de relieve estas notas de igualdad, rectitud y acoplamiento, la demostración de que el concepto de la equidad no puede ser divorciado del concepto de la justicia. Al mismo resultado nos lleva, como veremos, la investigación doctrinal, ya que lo que la tradición científica acusa vigorosamente es que la equidad es una especie de la justicia.

Al margen de su etimología, la equidad presenta una gran equivocidad terminológica. Por un lado, el término popular de la equidad es expresión del Derecho justo según el sentir del ethos social, aunque en ciertas ocasiones la equidad se ha considerado como un arbitrio peligroso. Por otro, en la acepción técnico-jurídica, la equidad se presenta como lo adecuado a la existencia concreta de la vida jurídica (por ejemplo, una compraventa será equitativa si hay una correspondencia entre el objeto y el precio). Aparece así la equidad como un criterio racionalizador de las fuerzas económicas que actúan en un sistema. Otra versión técnico-jurídica del término equidad es la que la presenta como sinónimo de justicia natural o de Derecho natural, en contraposición a la justicia positiva o al Derecho estricto. En este sentido, lo justo sería lo conforme al Derecho positivo y lo equitativo establecería la exigencia axiológica del Derecho natural.

\section{CONFIGURACIÓN HISTÓRICA DE LA EQUIDAD}

Para poder concretar un significado del término equidad parece necesario realizar una configuración histórico-doctrinal del mismo. Fue efectivamente Aristóteles el primero en sintetizar las dos dimensiones de la equidad: la dimensión interpretativa y la creativa. En su Ética a Nicóma- 
$c O^{5}$ presenta lo equitativo como lo justo, no en el sentido de lo legal, sino como corrección de las leyes; la equidad integra las leyes en lo que tienen de insuficiente debido a su generalidad. Y es que cuando las circunstancias son indeterminadas, también debe serlo la norma. De esta concepción aristotélica surge la consideración de la equidad como justicia del caso concreto, de donde nace también la tradicional concepción de la equidad como aplicación benévola de las leyes.

En su obra la Retórica ${ }^{6}$, Aristóteles sostiene que ser equitativo no es tener presente la letra, sino el espíritu de la ley. Por eso, la diferencia entre un árbitro, que decide según equidad, y un juez, que decide según la ley, es que el árbitro nace precisamente para dar fuerza a la equidad.

Aristóteles considera en sus dos grandes obras filosóficas, la Ética y la Retórica, la doble dimensión de la equidad: como un criterio hermenéutico del Derecho para mitigar la generalidad de la norma y como un principio creador de Derecho en la consideración de la norma según su espíritu. Estas dos dimensiones de la equidad son una constante histórica ${ }^{7}$.

Los romanos usaron la palabra aequitas para indicar el Derecho bajo el aspecto intrínseco y final, o sea, en su objeto y esencia ${ }^{8}$. De esta forma, representa muy claramente el principio informador del Derecho, que consiste en establecer aquellas condiciones y aquellos límites a la acción de cada individuo que en la conciencia del pueblo resultan iguales para todos, teniendo en cuenta las razones de cada uno y la relación con los demás asociados. Las normas jurídicas no siempre se adecuan a los fines del Derecho. Por ello, en ocasiones se origina una antítesis entre el ius o el iustum y lo aequum. Las Constituciones de Justiniano y los textos de los jurisconsultos interpolados por los compiladores recogían esta realidad contradictoria. Las palabras aequitas y aequus adquieren el sentido de benignidad, indulgencia con respecto a las circunstancias del caso apreciadas por el juez.

En el Derecho de los pueblos actuales tampoco tiene la equidad un sentido claro y unívoco ni en el plano lexicográfico ni en el científico. En el

5 ARISTÓteles, Etica a Nicómaco, lib. V, introducción de E. Lledó Í̃̃̃go y traducción de J. Pallí Bonet, Madrid, Gredos, 1988, p. 263.

6 Aristóteles, Retórica, lib. I, introducción y notas de Q. Racionero, Madrid, Gredos, 1990, pp. 285-287.

7 D'Agostino entiende que la epiqueya no es adaptación, sino creación; no mitigación moral de la aridez jurídica, sino un aspecto fisiológico de la dinámica del Derecho: un método que permite vitalizar la ley escrita con la no escrita en una mediación entre norma y realidad. Vid. F. D'Agostino, Il tema dell'equità nell'antichità Greca, Milano, Giuffrè-Instituto di filosofia dil Diritto dell'Univ. Di Roma, 1973, p. 204.

8 P. Bonfante, Instituciones de Derecho romano, Madrid, Reus, 1929, pp. 7 y ss. 
plano lexicográfico, el sentido moderno de la equidad acusa una idea vaga y compleja de sentido puramente relativo. La Real Academia Española, en su Diccionario de Autoridades, decía al referirse a la equidad: «En el uso más común se toma esta palabra por templanza y bondad de ánimo bien intencionado; por moderación en el rigor del uso de las leyes, y en cierto modo por equivalencia e interpretación, que mira más a la intención del legislador que a la letra y rigor de la ley» ${ }^{9}$. Pues bien, el propio Diccionario de Autoridades en sus ediciones últimas ya no emplea exactamente la misma fórmula; acusa todavía más la nota de relatividad al expresarse así: «Equidad. Bondadosa templanza habitual. Propensión a dejarse guiar, o a fallar, por el sentimiento del deber o de la conciencia, más bien que por las prescripciones rigurosas de la justicia o por el texto terminante de la ley». En nuestro texto académico no están muy marcadas las dos principales acepciones históricas del término equidad, como justicia natural la una y como justicia aplicada benignamente la otra.

Parece evidente que en el ambiguo concepto moderno de equidad predomina el sentido de equidad civil sobre el de equidad natural. El concepto puro de equidad natural está hoy embebido de otras ideas como las de moral, Derecho natural, ideal social... Por otra parte, cuando los códigos modernos aluden expresamente a la equidad o lo equitativo (por ejemplo, los arts. 1.154 y 1.690 del Código Civil español) no parecen referirse a principios o ideales generales, sino a normas de conducta o de juicio muy particularizadas.

El concepto moderno de equidad gira en torno a dos ideas distintas: la idea aristotélica de norma individualizada (epiqueya de los griegos) y la idea cristiana de mitigación del rigor de la ley para un caso particular (bumanitas, benignitas). Así, el concepto general o amplio de la equidad es el de adaptación del Derecho a la realidad mediante la apreciación exacta de todos los elementos de hecho que en el caso concurran, y el concepto más restringido, el de adaptación del Derecho a las particularidades del caso concreto, para dar a éste un tratamiento más blando y benévolo. Con todo, en la esfera del Derecho civil, la idea de benignidad no parece poder ser aplicable fuera de aquellos casos en los que la humanización de la ley ha de tenerse en cuenta con respecto a instituciones configuradas con caracteres rígidos y formalistas. La benignidad del juez hacia una de las partes puede implicar injusticia hacia la otra. El juicio benévolo es unilateral, y precisamente la nota esen-

9 Diccionario de Autoridades de la Real Academia Española, t. III, Madrid, Francisco del Hierro, 1732, p. 739. 
cial del Derecho y de la justicia es la alteridad, la consideración de ambas partes. La objeción fundamental contra el concepto de equidad suavizadora ya la formuló Santo Tomás de Aquino cuando indicaba que la equidad no debe oponerse a la severidad, sino al ius strictum, ya que muchas veces aquello que es severo es equitativo ${ }^{10}$. Y sólo cuando la justicia legal se entiende como mera sujeción a la ley, en el sentido literal de ésta, la epiqueya no se contiene en la justicia legal, sino que la excede y es superior a ella.

Entre los modernos filósofos del Derecho, Stammler señala tres distintas acepciones del término equidad. Ésta puede referirse a lo fundamentalmente justo (identificándose con la noción de justicia), a la norma elegida como justa para juzgar un caso concreto litigioso o a la norma que se adopta en aquellos casos en que se trata de establecer un límite entre los litigantes en materias totalmente indeterminadas (arbitrio de equidad) ${ }^{11}$. Como podemos observar, la idea de equidad, tal como hoy la concebimos, ha sido el producto de aportaciones históricas y doctrinales diversas.

En todo caso, sea cual sea la posición que hoy se adopte en orden a los problemas filosóficos y sociológicos del Derecho, si se superan los puntos de vista del positivismo y del formalismo jurídico llevados a sus últimas consecuencias, se debe reconocer que junto al Derecho estatuido emanado de las fuentes formales del Derecho (principalmente ley y costumbre) hay un Derecho no formulado, no estatuido, llamado de diversas maneras - Derecho natural, discrecional, no oficial, Derecho vivo, social, intuitivo, libre, científico-, que constituye un Derecho extralegal que, llegado el caso litigioso, las partes, sus consejeros o el juez han de extraer de su conciencia, de las concepciones morales o de la apreciación directa de los hechos sociales, sin la intermediación de las fuentes oficiales. A esta esfera y no a la del Derecho formulado pertenece el criterio o principio de la equidad. La equidad actúa entonces sobre el Derecho legislado, en cuanto puede ser criterio de comparación para juzgar las normas positivas. La ley actúa sobre la equidad en cuanto que señala los límites dentro de los cuales la equidad puede ser aplicada. La doctrina actual ha centrado sus esfuerzos en la configuración y determinación de la dinámica de este Derecho vivo y extralegal que actúa en la resolución de los problemas jurídicos. De esta manera, se centra la atención en el área de contacto real entre la conducta de los jueces y la conducta de la gente.

10 Tomás de Aquino, Summa Theologicae, pars. 11. ${ }^{\circ}$, questio CXX, art. 2, 11. ed., Madrid, Bibilioteca de Autores Cristianos, p. 329.

${ }^{11}$ R. Stammler, Tratado de filosofía del Derecho, 2. ${ }^{a}$ ed. alemana traducida por W. Roces, Madrid, Reus, 1930, p. 383. 
Desde esta perspectiva, el realismo jurídico norteamericano, con Karl N. Llewellyn y Jerome Frank a la cabeza ${ }^{12}$, representa una nueva forma de concebir el Derecho por los juristas que ya había sido apuntada por Roscoe Pound y su jurisprudencia sociológica ${ }^{13}$.

La configuración del término equidad se ha producido de forma simultánea a la evolución de su aplicación histórica. Los grandes y trascendentales avances en el Derecho romano se deben, en gran medida, a la aplicación del ius aequum. Muestra de ello son la estimación de la libertad humana, el reconocimiento y gradual predominio de los vínculos de sangre sobre los del parentesco civil o la condenación del enriquecimiento indebido, entre otros. En el Derecho bizantino y justinianeo la concepción de la equidad se afina con la incorporación de nuevas notas. Los primeros matices que, fruto de una doble influencia - la de la cultura griega y la del cristianismo- adopta en este periodo la idea de equidad, podemos condensarlos en los tres siguientes: la equidad como justicia natural, la equidad como criterio orientador de la función del juez y de una interpretación flexible del Derecho en contraposición al ius strictum, y la equidad como criterio de aplicación benigna y humana.

Entre los siglos intermedios hasta el siglo XVIII, la equidad atraviesa dos etapas diferentes: la primera, de espontaneidad y naturalidad jurídica, de predominio del Derecho consuetudinario; la segunda, de renacimiento romanista y consiguiente restauración del espíritu dogmático del Derecho justinianeo. En la primera etapa resalta la gran importancia que se atribuía a la equidad judicial. La costumbre y las decisiones judiciales se debían completar como fuentes de creación del Derecho. Respecto de la segunda etapa, puede observarse un progresivo paso del Derecho consuetudinario al Derecho imperativo y científico.

El renacimiento romanista tuvo, en realidad, matices muy diversos. En algunos países y momentos fue intenso y profundo el fenómeno de recepción del Derecho romano, pero fuera de ello quedan, durante el largo proceso de la Edad Media, muchos espacios en los que el Derecho disfruta

${ }^{12}$ Especialmente significativa para la comprensión del realismo jurídico es la obra de K. Llewellyn, A Realistic Jurisprudence: The Next Step, la traducción al castellano es de P. Casanovas, «Una teoría del Derecho realista: el siguiente paso», en P. Casanovas y J. J. Moreso (eds.), El ámbito de lo jurídico. Lecturas del pensamiento jurídico contemporáneo, Barcelona, Crítica-Grijalbo, 1994, pp. 244-293.

13 Pound afirma que es necesario «medir las reglas legales y doctrinas e instituciones jurídicas por la extensión en que realizan o favorecen los fines por los que existe el Derecho». Vid. R. Pound, An Introduction to the Philosophy of Law, New Haven, Yale Univiversity Press, 1959, p. 43. 
de toda su espontaneidad y la equidad se desenvuelve libremente. A ello también colabora el desarrollo de las teorías sobre el Derecho natural, que pretenden vencer el formalismo e infiltrar en el Derecho la recta conciencia, la moral y la justicia. En definitiva, en la esfera de lo jurídico puede afirmarse que la equidad tuvo una especial importancia en esta época histórica; así, por ejemplo, el Derecho mercantil, en sus orígenes, fue una creación de la equidad.

En los países continentales, en el siglo XVI, comienza y va acentuándose progresivamente una corriente doctrinal que se preocupa del excesivo campo que se concedía a la equidad, de los peligros inherentes al arbitrio que ésta suponía y de la ofensa que significaba para las leyes escritas. Se abre así la época de crítica contra la llamada equidad cerebrina y, en general, contra todo el sistema de equidad.

A fines del siglo XVIII el proceso estaba cumplido, y es durante el siglo XIX cuando sobreviene una marcada fase de madurez y estabilidad jurídica, acompañada de un rígido legalismo. Pero el ambiente de desconfianza en torno al arbitrio judicial y la equidad había asomado ya en los escritos jurídicos de los siglos que precedieron al siglo XIX. A menudo se restringía el uso de la equidad sólo a los casos en que la ley lo autorizase. En este sentido, Juan Francisco de Castro señala que «los doctores antiguos restringían frecuentemente el uso de la equidad por los jueces a sólo la equidad estricta, cortándoles la facultad de extenderla fuera de los casos y circunstancias en las mismas leyes prevenidas» ${ }^{14}$. Este hecho se acentuó en la época de la codificación.

En general, bajo el imperio de los Códigos Civiles modernos no es reconocida la equidad como norma de Derecho que pueda actuar fuera de los principios de la ley, y mucho menos contra ella. Los civilistas franceses hablan poco de la equidad. La llamada Escuela de la Exégesis no podía mostrarse favorable a admitir la aplicación de fuentes o elementos jurídicos distintos de la ley misma y que pudieran entrar en contradicción con ella. No obstante, hay comentaristas que reconocen el valor de la equidad como complemento necesario de la ley y la costumbre. Gény comenta: «Hay que confesar que se hace esta concesión no sin repugnancia y como una consecuencia inevitable que se intenta aminorar en la persuasión, más o menos sincera, de que la equidad se encuentra siempre, a lo menos en

${ }^{14}$ J. F. DE CASTRO, Discurso crítico sobre las leyes y sus intérpretes, t. I, 2. ${ }^{a}$ ed., Madrid, Imprenta de E. Aguado, 1829, p. 186 (la 1. ${ }^{a}$ ed. es de 1765). El discurso demuestra la incertidumbre de los intérpretes y la necesidad de un nuevo y metódico cuerpo de Derecho para la recta administración de la justicia. 
germen y por vía de inducción, en la ley misma» ${ }^{15}$, y es de notar que el propio Laurent, cuya obra señala el apogeo de la Escuela, no sólo admite la doctrina de que los contratos deben interpretarse con espíritu de equidad, pese a que al juez no le esté permitido romper las convenciones de las partes para sustituirlas por otras que le parezcan más equitativas ${ }^{16}$, sino también la doctrina según la cual «en el silencio de la ley, la obligación de fallar impuesta al juez da a éste, en cierto modo, una parte en el ejercicio del poder legislativo, haciéndole, según la expresión de Portalis, ministro de la equidad $\gg^{17}$. Se acepta, de esta manera, el valor interpretativo y creador de la equidad como pieza clave para aplicar el Derecho al caso concreto.

Podemos concluir esta breve referencia al desarrollo histórico de la equidad en el continente europeo, haciéndonos eco de la afirmación de Castán Tobeñas: «Los tipos a través de los cuales se ha manifestado la equidad en la cultura occidental están históricamente muy entrelazados. Esto explica que, aunque sean muy variadas las concepciones modernas de la equidad, no deja de haber muchos puntos de conexión entre las que pueden considerarse como las nociones primarias, a saber: la que considera la equidad como lo que es conforme a los cánones del Derecho (o sea, a la conciencia jurídica humana o al Derecho natural) y la que la considera como lo que se adapta a las características especiales del caso que ha de juzgarse» ${ }^{18}$.

Respecto a la Equity anglosajona, su contraposición con un Derecho formal o estricto, tan característico en Roma, matiza también el Derecho inglés, cuyo desarrollo guarda mucha semejanza con el Derecho romano. En ambos sistemas jurídicos, las normas rígidas y formales fueron gradualmente mitigadas por un sistema de jurisprudencia de equidad ${ }^{19}$. La Equity, según su definición histórica, era «un cuerpo de reglas jurídicas que tuvieron por origen primero no la costumbre o la ley escrita, sino los imperativos de la conciencia, reglas excepcionalmente obtenidas y desenvueltas por

${ }^{15}$ F. GÉNY, Méthode d' interprétation et sources en Droit privé positif: essai critique, Paris, Librairie Générale de Droit et de Jurisprudence, 1995 (véase la trad. española editada en Madrid, Hijos de Reus, 1902, núm. 19, p. 34; también la más reciente Método de interpretación y fuentes en el Derecho privado positivo, con prólogo de R. SALEILLES y estudio preliminar sobre el pensamiento científico jurídico de F. Gény por J. L. Monereo Pérez, Granada, Comares, 2000).

${ }^{16}$ F. Laurent, Principles de Droit Civile Français, t. XXV, Bruxelles, Bruylant-Christophe \& Cie., 1878, p. 247.

17 Ibid., t. I, 1869 , pp. 328 y ss.

18 J. CAstán TobeÑAs, La equidad y sus tipos bistóricos, discurso de recepción en la Real Academia de Ciencias Morales y Políticas, Madrid, Reus, 1950 p. 66.

19 E. Bodenheimer, Teoría del Derecho, $4 .^{\text {a }}$ reimp. en español con traducción de V. Herrero, México, Fondo de Cultura Económica, 1942, p. 289. 
ciertos tribunales de justicia, especialmente por el de la Cancillería» ${ }^{20}$. La aequitas romano-canónica sirvió de base al origen y la función que desarrolló esta jurisdicción de la equidad como sistema complementario de la Common Law, esencialmente formal, tradicional y empírica. Las Doce Tablas de la Equidad anglosajona son una prueba patente de ello; estos enunciados se han convertido hoy en principios de Derecho, más aún, en normas, al ser vinculantes por el juego de los precedentes. Además, a partir del siglo XIX las dos fuentes del Derecho inglés, Common Law y Equity, tienden a consolidarse en un único ordenamiento sustantivo y jurisdiccional, pero dándose preferencia a la Equity en caso de contradicción ${ }^{21}$.

\section{PROPUESTA DE UN CONCEPTO DE EQUIDAD}

La equidad es una idea polifacética. En gran medida se trata de un sentimiento, para algunos, individual, y para otros, colectivo. Pero hay que tener en cuenta que en el Derecho los factores emocionales han de estar subordinados a los factores morales objetivos. Por ello, en la consideración de la equidad ha de predominar, sobre el aspecto del sentimiento, el de la exigencia de carácter ético. La equidad es, en este sentido, un atributo ético-jurídico del Derecho, muy relacionado con el aspecto de la equidad como virtud que presentaban Aristóteles y Santo Tomás de Aquino. También es la equidad un método de elaboración jurídica y aplicación de una determinada norma a un caso concreto. Por ello, la equidad, en un principio, no es una norma jurídica, sino más bien una propiedad o cualidad que toda norma de Derecho puede tener cuando en su aplicación a las relaciones concretas realiza las exigencias de la justicia. Pero en muchas ocasiones la equidad sí se traduce en normas por vía legislativa, consuetudinaria o judicial ${ }^{22}$.

${ }^{20}$ H. LÉvy-Ullmann, Éléments d'Introduction Générale à l'étude des sciences juridiquesII, le système juridique de l'Anglaterre; I: le sistème traditionnel, Paris, Sirey, 1928, p. 431.

${ }^{21}$ Las leyes de judicatura de 1873, 1875 y 1925 crean la Supreme Court que resuelve conforme a ambas fuentes de Derecho, completadas por las leyes dictadas por el rey y el Parlamento. Sin embargo, como señala Torralba Soriano, puede decirse que, pese a que la Equity se parece mucho al Common Law por la técnica del precedente, subsisten varias características propias. La Equity deja mayor margen a la buena fe que el Common Law y, además, permite ir más lejos que el Common Law, dando mayor flexibilidad al Derecho. Vid. V. Torralba Soriano, en M. Albadalejo y S. Díaz Alabart (dirs.), Comentarios al Código Civil y compilaciones forales, t. I, Madrid, Revista de Derecho Privado, 1992, p. 536.

22 Vid. J. CASTÁn TOBEÑAs, La idea de equidad y su relación con otras ideas morales y jurídicas afines, Madrid, Reus, 1950, p. 57. 
Junto con lo anterior, para aventurarse a establecer un concepto unitario de equidad también hay que tener en cuenta las diferentes formas o tipos de equidad que pueden presentarse en la interpretación y aplicación de las normas jurídicas. En primer lugar, la equidad puede desempeñar un papel de interpretación ayudando al juez en la indagación del verdadero sentido de la norma jurídica (se trata de la equidad secundum legem). Esta forma de equidad presenta la dimensión hermenéutica de la misma. Supone una forma de razonamiento dialéctico en la que se parte de premisas verosímiles y necesarias desde donde se interpreta el caso. En segundo lugar, la equidad puede servir de criterio de aplicación del Derecho al margen del orden positivo (estamos ante la equidad praeter legem). Este tipo de equidad opera cuando no hay norma de Derecho que regule directamente una determinada relación ni cabe extraerla del sistema positivo por la vía de analogía o de sus principios informantes. Parece razonable que, a falta de otras fuentes, la equidad pueda y deba intervenir, permitiendo al juez establecer aquella norma que se desprenda de los principios supremos de Derecho natural adaptados a las circunstancias del caso particular. Así lo reconoce la mayoría de los autores. Muchas veces la referencia a la equidad se encubre con fórmulas modernizadas más o menos aceptables. Se dice así que el juez, al no haber ley ni, por consiguiente, interpretación posible, deberá establecer la norma que se derive de la intuición directa del caso y de las exigencias que se dimanen de la naturaleza misma de las cosas, o bien que el juez deberá hacer lo que haría el legislador: buscar científicamente en el Derecho que late en la vida social la norma que en el caso específico deba aplicarse. Finalmente, se plantea la posibilidad de utilizar criterios de equidad en la aplicación del Derecho, incluso en contra de lo establecido en la norma positiva (se trata de la equidad contra legem).

No obstante lo anterior, lo fundamental para definir la equidad es tener en cuenta cuál es su contenido. Como la equidad es parte de la justicia, su contenido ha de ser esencial y fundamentalmente el propio de ésta. Sin embargo, parece una tarea imposible el intentar predeterminar los principios de la equidad. Ello se debe a los matices propios que, por razón de su especialidad, contiene el concepto y función individualizadora de esta última. No es posible asignar a la equidad contenido material alguno, pues, como ya hemos dicho, la equidad no es propiamente una norma, sino un principio directivo que opera sobre el Derecho positivo. La equidad se sitúa entonces fuera del ordenamiento positivo. Además, dada la variabilidad de las circunstancias de tiempo, lugar y hecho concreto que en el juicio equitativo han de ser contempladas, es imposible formular principios 
absolutos de equidad. En definitiva, «dependiendo esencialmente la equidad de las circunstancias particulares de cada caso considerado individualmente, no puede sentarse ninguna regla establecida ni ningún precepto fijo de equidad sin destruir su verdadera esencia y reducirla a no ser más que un Derecho positivo» ${ }^{23}$. Lo que sí puede intentarse es señalar el contenido formal del juicio de equidad.

El juicio de equidad supone una facultad de apreciación discrecional, pero no arbitraria. Cuando se dice que el juez o el amigable componedor debe decidir según equidad es como si se dijera que debe fallar según su conciencia o según su criterio discrecional. Pero este poder discrecional del juez no puede equipararse a lo arbitrario. La actuación del juez autorizado para decidir según equidad es libre, en el sentido de que no está ligado por ningún Derecho fijado en fuentes formales, pero no lo es en el sentido de que pueda regirse por criterios y apreciaciones puramente subjetivos. Si esto ocurriera, de nuevo nos encontraríamos ante la tradicionalmente llamada aequitas cerebrina, el arbitrio más perturbador del principio de seguridad del Derecho. Como dice Del Vecchio: «La obra del intérprete, en tanto y cuanto se dirige a abrazar e integrar un sistema históricamente determinado, no puede ser cerebrina, es decir, arbitraria e individual» ${ }^{24}$.

La moderna doctrina científica proclama sin cesar que la aplicación por parte del juez de la equidad no puede significar la aplicación del puro arbitrio personal. El criterio por el que decide según equidad debe fundamentarse en razones objetivas. En realidad, esta doctrina es muy antigua, ni siquiera en los juicios romanos bonae fidei — cuando el juez había de buscar la solución de las cuestiones en los principios de aequum et bonuum - existía para él la facultad de decidir por puro arbitrio; su arbitrio era boni viri: estaba obligado a fallar según la buena fe. En este sentido, el ilustre civilista De Diego se manifiesta así: «El fallo que en todo caso han de dar los jueces y tribunales no puede ser arbitrario ni responder a otro criterio que el de la justicia. El juez es órgano del Derecho, y según y conforme a él ha de dar el fallo. No es su personal concepción de lo justo y del Derecho lo que ha de reflejarse en éste, pues ello le quitaría acierto, certidumbre y seguridad a la vida jurídica (y sin ellas ésta no puede moverse con desembarazo), sino lo que sea tenido por tal y aparezca como tal en signos indubitables, generales, objetivos, que responden a la concepción

23 W. Blackstone, Commentaries on the Laws of England in Four Books, 15. a ed., London, A. Strahan, 1809; citado por H. Lèvy-Ullmann, Le système juridique de l'Anglaterre, t. I, Paris, Sirey, 1928, p. 443.

${ }^{24}$ G. Del Vecchio, Los principios generales del Derecho, 2. ${ }^{a}$ ed., Barcelona, Bosch, 1949. 
dominante en el momento y país de la cuestión, llámense como se llamen esos signos: ley, costumbre, equidad, principios de Derecho, etc.» ${ }^{25}$.

En orden a determinar mejor el contenido de la equidad, hay que tener en cuenta los diversos factores que influyen en la configuración de un juicio basado en este criterio ${ }^{26}$. Algunos son factores de tipo intuitivo e irracional (muy relevantes en la Escuela alemana de Derecho Libre, de gran propagación en Norteamérica), si bien hay que tener en cuenta que el posible juicio intuitivo del juez no es, en la mayoría de los casos, otra cosa que la aplicación de su ciencia jurídica y experiencia profesional. También se dan factores sociológicos (de gran relevancia entre empiristas y positivistas). Según Windscheid, la equidad recibe su contenido de la conciencia jurídica de quien toma en consideración un determinado Derecho, aunque reconoce que puede existir no sólo un sentimiento jurídico y una conciencia jurídica individual, sino también un sentimiento jurídico de todo el pueblo; caso este último en que la equidad señala el ideal que el Derecho de aquel pueblo debe realizar ${ }^{27}$. El juicio de equidad también puede estar determinado por un factor político (comprendido realmente dentro del grupo de los sociológicos y de gran relevancia en el realismo norteamericano), pues, al igual que el Derecho, la equidad tiene un elemento político al lado del ético. Ya en la Edad Media la referencia a la política fue muchas veces una especie de carta blanca concedida a los jueces para que pudiesen aplicar el Derecho romano y canónico. Precisamente en esta concurrencia de elementos políticos está uno de los más serios peligros de la equi$\mathrm{dad}^{28}$. Sin duda, el factor racional es el que tiene más peso para realizar un juicio de equidad. Supone la consideración de los principios del Derecho natural y de los principios generales del ordenamiento jurídico. Stammler encuadra este factor racional del juicio de equidad dentro de su teoría del Derecho justo: «Cuando la ley renuncia a regular ciertas cuestiones, a dic-

${ }^{25}$ F. C. DE Diego, Curso elemental de Derecho civil español, común y foral, Madrid, Librería General de Victoriano Suárez, 1926.

${ }^{26} \mathrm{El}$ análisis de estos factores lo desarrolla J. CASTÁn ToBeñAs, La idea de equidad..., op. cit., pp. 65 y ss.

${ }_{27}$ B. WindscheID, Diritto delle Pandette. Note e referimenti al Diritto civile italiano, t. IV, Torino, UTET, 1930, p. 33.

${ }^{28}$ Con referencia a este factor político, GUTTERIDGE afirma: «Los principios de la equidad son de naturaleza fluida y susceptibles de recibir influencias que actúan al margen del Derecho, tales como las ideas morales del momento, ideologías políticas y cambios económicos y políticos en la estructura de la sociedad humana, por lo que su aplicación requiere gran cautela para evitar que puedan socavar o suplantar las normas ordinarias y efectuar cambios radicales en el Derecho por medios indirectos». Vid. H. C. GutTERIDGe, Comparative Law, Cambridge, Cambridge University Press, 1946, p. 95. 
tar artículos precisos y taxativamente determinados, optando por remitir a las partes, a sus consejeros y al juzgador que intervenga en el litigio, a su propio arbitrio o a la equidad, no quiere decir otra cosa sino que en cada caso se habrá de elegir la norma jurídica que refleje la solución fundamentalmente justa [...] No basta confiar la resolución al sentimiento natural del derecho de quien ha de juzgar ni tampoco al libre arbitrio del juez. Cuando se habla de libre arbitrio judicial se olvida que el juez no puede sentenciar jamás libremente, llevado por sus caprichos subjetivos, sino que debe fundamentar objetivamente sus resoluciones» ${ }^{29}$.

Las fórmulas de los principios generales del Derecho y de la equidad, que pueden agrupar orgánicamente muchos elementos de naturaleza distinta y a las que la actual doctrina científica concede gran amplitud y una gran trascendencia, fueron ya vislumbradas por nuestros clásicos. Suárez marcaba la diferencia entre ambos criterios y concibió el juicio de equidad como un acto o juicio de prudencia, subordinado no a las palabras de la ley, sino a los principios generales del Derecho natural e incluso también del Derecho humano, en cuanto dependa de ellos en particular ${ }^{30}$. Resaltan aquí los elementos subjetivos, propios de la prudencia como virtud, al lado de los elementos objetivos, contenidos en los principios generales del Derecho.

Como puede verse, es difícil establecer un concepto unitario de la equidad. Castán Tobeñas ${ }^{31}$ lo intenta y considera que para hacer posible esta tarea y conseguir un concepto que abarque todas las acepciones y aplicaciones de la misma, reduciéndolas en cuanto sea posible a un solo principio, hay que partir de lo siguiente: en primer lugar, la equidad se forma fuera del Derecho positivo, aunque actúe precisamente sobre él; en segundo lugar, hay que considerar la equidad no como algo desligado de la justicia o que corrige sus soluciones, sino como una especie de la propia justicia que realiza su mayor perfección; además, la especialidad del criterio de equidad, a diferencia del criterio general de justicia, radica en que se toma en consideración, más que los elementos formales, el sentido humano que ha de tener el Derecho positivo, y más que los esquemas generales de la norma jurídica, la adecuación de ésta a las circunstancias del caso concreto; en cuarto

29 R. Stammler, Tratado de filosofía del Derecho, op. cit., pp. 17 y ss.

${ }^{30}$ F. SuÁREZ, Tractatus de Legibus ac Deo Legislatore, lib. VI, versión española de J. Torrubiano con el título Tratado de las leyes y de Dios legislador, t. I, Madrid, Hijos de Reus, 1918, p. 95 (hay otra edición que aquí también se considera de E. MuniozGurEn, Madrid, Instituto de Estudios Políticos, 1968).

31 J. CASTÁn ToBeñas, La formulación judicial del Derecho y el arbitrio de equidad, 2. ${ }^{a} \mathrm{ed}$. revisada y aumentada, Madrid, Reus, 1954, pp. 129-158. 
lugar, la equidad implica, más que una justicia abstracta, una justicia individualizada, y más que una justicia estrictamente legal, una justicia de tipo natural y moral; a lo anterior hay que añadir que, en algunos casos, la equidad puede suponer una justicia benévola, pero su característica general es más bien la de constituir una justicia flexible y humanitaria, no rígida y formalista (es función práctica de la equidad la de templar el rigor de las leyes positivas y corregir y suplir sus deficiencias en vista de las singularidades de cada relación y caso); por último, hay que tener en cuenta que la equidad es un criterio de justicia que toma en consideración no sólo las ideas generales del Derecho y el sistema jurídico, sino especialmente las particularidades del caso concreto, y que trata de darle solución, más que con sentido estrictamente legal, con sentido moral y humano.

Siguiendo estos criterios, la definición de equidad que propone Castán Tobeñas es la siguiente: «equidad es el criterio de determinación y de valoración del Derecho que busca la adecuación de las normas y de las decisiones jurídicas a los imperativos de la ley natural y de la justicia, en forma tal que permita dar a los casos concretos de la vida, con sentido flexible y humano (no rígido y formalista), el tratamiento más conforme a su naturaleza y circunstancias» ${ }^{32}$.

\section{LA APLICACIÓN DE LA EQUIDAD EN VIRTUD DE LA ÉTICA MATERIAL QUE DEBEN TENER LAS NORMAS POSITIVAS}

En principio, hay que apoyar la posibilidad —e incluso la necesidadde que el juez acuda a la equidad, aún sin estar autorizado para ello por una remisión legislativa.

No obstante, el principio general que acabamos de señalar tiene los límites que en cada ordenamiento le impongan las fuentes legislativas, por ser éstas las predominantes en la organización política moderna. «El juez escribe Legaz- está vinculado a la ley, la cual puede denegar al juez toda libertad de acción, puede negarle jurídicamente acceso a la equidad, pero a la larga esto es casi un imposible; la ley es menos poderosa, menos eficiente de lo que ella piensa de sí, y el juez posee jurídicamente más poder que

32 J. Castán Tobeñas. La idea de equidad y su relación con otras ideas, morales y jurídicas afines, discurso pronunciado en la solemne apertura de los tribunales el 15 de septiembre de 1950, Madrid, Reus, 1950, p. 51. 
el que él mismo se atribuye cuando interpreta demasiado restrictivamente las normas que se lo conceden ${ }^{33}$. Para remediar la posible discrepancia entre la consideración racional de las fuentes del Derecho positivo y la actividad del juez resulta necesario considerar el carácter de cada norma legal: «El juez — dice Puig Brutau- es libre para juzgar dentro de ciertos límites que señalan las normas, y es preciso hacer un detenido análisis de la diversa naturaleza de ésta, es decir, de su diverso grado de abstracción o generalidad, para percibir cuáles son dichos límites» ${ }^{34}$. Es lógico que, así como las reglas elásticas y flexibles permiten por su propia naturaleza la aplicación de la equidad, las normas de Derecho estricto prescinden de ella, en aras a salvaguardar la seguridad jurídica y la certeza del Derecho.

La ética social puede perfectamente establecer máximas bic et nunc, esto es, líneas directrices de la ética social, pero no esquemas normativos de validez general bajo los cuales pueda subsumirse un determinado supuesto de hecho mediante juicios analíticos. Buena fe o buenas costumbres no son moldes acabados que el juez calca sencillamente sobre el material que ha colocado debajo, sino una extraordinaria tarea que tiene que realizar el propio juez en la situación determinada de cada caso jurídico. En este sentido, Hans Welzel no admite la posibilidad de que el juez emita juicios éticosociales de validez general ${ }^{35}$. La doctrina actual sobre la aplicación judicial del Derecho — superada la teoría de la subsunción y admitida la labor de individualización de la norma por parte del juez, así como la trascendencia de su acto volitivo de decisión, a la hora de dictar sentencia - ${ }^{36}$ nos obliga a considerar la presencia y complejidad de numerosos elementos jurídicos que se manifiestan en la aplicación de la norma al caso concreto.

Así pues, que la aplicación del Derecho no se limita a la realización de una figura lógica acabada, esto es, de un juicio analítico, sino que es siempre interpretación, es un hecho aceptado por la mayoría de los juristas. Rara vez la configuración general de la norma jurídica permite, ante las inagotables posibilidades de los concretos conflictos, una concreción que haga que sean suficientes simples juicios analíticos. La aplicación judicial del Derecho es, como toda interpretación, realización del valor, es decir, una elección entre varias valoraciones posibles hacia cuyos principios aquélla se orienta.

33 L. Legaz y Lacambra, Filosofía del Derecho, Barcelona, Bosch, 1979, p. 465.

34 J. PUIG BRUTAu, La jurisprudencia como fuente del Derecho: interpretación creadora y arbitrio judicial, Barcelona, Bosch, 1951?, p. 38.

${ }^{35}$ Cfr. H. Welzel, Introducción a la filosofía del Derecho, Derecho natural y justicia material, traducción de F. González Vicén, 2. ${ }^{a}$ ed., Madrid, Aguilar, 1971 (la 3. ${ }^{a}$ reimp. es de 1979).

36 J. Almoguera, Lecciones de Teoría del Derecho, Madrid, Reus, 1995, pp. 278 y ss. 
En este sentido, cada decisión constituye un elemento de una nueva creación de Derecho. Y ello es tanto más así cuanto más indeterminada sea la prescripción del legislador, y de manera especialísima en el caso del criterio de equidad al que a menudo se hace alusión de manera expresa o implícita, por ejemplo, en las cláusulas generales. Por ello, la aplicación de este criterio contribuye a la creación del Derecho futuro, trazando una línea cuya dirección no puede establecerse previamente.

En definitiva, nos hallamos ante directrices que, como tales, remiten a su vez a una significación a encontrar, esto es, directrices referidas al caso. La equidad, así concebida, es una máxima de actuación justa que invita a orientarse en líneas de tendencia.

\section{BIBLIOGRAFÍA}

ARISTóteles, Ética a Nicómaco, lib. V, introducción de E. LLEDó ÍñIGO y traducción de J. Pallí Bonet, Madrid, Gredos, 1988.

- Retórica, lib. I, introducción y notas de Q. Racionero, Madrid, Gredos, 1990.

Agostino, F. D, Il tema dell'equità nell'antichità Greca, Milano, Giuffrè-Instituto di filosofia dil Diritto dell'Univ. Di Roma, 1973.

Almoguera, J., Lecciones de Teoría del Derecho, Madrid, Reus, 1995.

Álvarez, U., Curso elemental de Derecho romano, vol. 1, Madrid, Estades, 1948.

Bodenheimer, E., Teoría del Derecho, $4 .{ }^{a}$ reimp. en español con traducción de V. Herrero, México, Fondo de Cultura Económica, 1942.

Bonfante, P., Instituciones de Derecho romano, Madrid, Reus, 1929.

CASTÁn ToBeÑas, J., Teoría de la aplicación e investigación del Derecho: metodología y técnica operativa en Derecho privado positivo, Madrid, Reus, 1947.

- La idea de equidad y su relación con otras ideas morales y jurídicas afines, discurso de apertura de Tribunales, Madrid, Reus, 1950.

- La equidad y sus tipos históricos en la cultura occidental europea, discurso de recepción en la Real Academia de Ciencias Morales y Políticas, Madrid, Reus, 1950.

- La formulación judicial del Derecho (jurisprudencia y arbitrio de equidad), 2. ${ }^{a}$ ed. revisada y aumentada, Madrid, Reus, 1954.

Castro, J. F. de, Discurso crítico sobre las leyes y sus intérpretes, vol. I, 2. ${ }^{a}$ ed., Madrid, Imprenta de E. Aguado, 1829.

Diccionario de Autoridades de la Real Academia Española, t. III, Madrid, Francisco del Hierro, 1732.

Diccionario de Autoridades de la Real Academia Española, Madrid, Gredos, 1990.

Gutteridge, H. C., Comparative Law, Cambridge, Cambridge University Press, 1946. 
Hervada, J., Introducción crítica al Derecho natural, Pamplona, EUNSA, 1987.

- Lecciones de filosofía del Derecho, Pamplona, EUNSA, 1992.

Laurent, F., Principles de Droit Civile Français, t. XXV, Bruxelles, BruylantChristophe \& Cie., 1878.

Legaz y Lacambra, L., Amor, amistad y justicia, Madrid, Real Academia de Jurisprudencia y Legislación, 1969.

- Filosofía del Derecho, Barcelona, Bosch, 1979.

Lévy-Ullmann, H., Éléments d'Introduction Générale à l'étude des sciences juridiques-II, le système juridique de l'Anglaterre; I: le sistème traditionnel, Paris, Sirey, 1928.

- Le système juridique de l'Anglaterre, t. I, Paris, Sirey, 1928.

Llewellyn, K., A Realistic Jurisprudence: The Next Step, la traducción al castellano es de P. CASANOVAS, «Una teoría del Derecho realista: el siguiente paso», en P. Casanovas y J. J. Moreso (eds.), El ámbito de lo jurídico. Lecturas del pensamiento jurídico contemporáneo, Barcelona, Crítica-Grijalbo, 1994.

Monereo Pérez, J. L., Método de interpretación y fuentes en el Derecho privado positivo, con prólogo de R. SALEILlES y estudio preliminar sobre el pensamiento científico jurídico de Gény, Granada, Comares, 2000.

Pound, R., An Introduction to the Philosophy of Law, New Haven, Yale University Press, 1959.

Puig Brutau, J., La jurisprudencia como fuente del Derecho: interpretación creadora y arbitrio judicial, Barcelona, Bosch, 1951.

Stammler, R., Tratado de filosofía del Derecho, 2. ${ }^{a}$ ed. alemana traducida por W. Roces, Madrid, Reus, 1930.

SuÁrez, F., Tractatus de Legibus ac Deo Legislatore, lib. I, cap. II (hay versión española de J. Torrubiano, Tratado de las leyes y de Dios legislador, t. I, Madrid, Hijos de Reus, 1918).

Welzel, H., Introducción a la filosofía del Derecho, Derecho natural y justicia material, traducción de F. González Vicén, 2. ${ }^{a}$ ed. Madrid, Aguilar, 1971 (la 3. a reimp. es de 1979).

WindsCHeID, B., Diritto delle Pandette. Note e referimenti al Diritto civile italiano, t. IV, Torino, UTET, 1930.

Wohlhaupter, E., «La importancia de la equidad en la historia del Derecho de España», Revista de Investigación y Progreso, año IV, núm. 10 (1930).

Vecchio, G. del, Los principios generales del Derecho, 2. ${ }^{a}$ ed., Barcelona, Bosch, 1949. 